\title{
Blood Pressure Control versus Atrial Fibrillation Management in Stroke Prevention
}

\author{
Carmine Savoia $^{1} \cdot$ Lidia Sada $^{1} \cdot$ Massimo Volpe $^{1,2}$
}

(C) Springer Science+Business Media New York 2015

\begin{abstract}
Hypertension is one of the major risk factors for atrial fibrillation which in turn is the most prevalent concomitant condition in hypertensive patients. While both these pathological conditions are independent risk factors for stroke, the association of hypertension and atrial fibrillation increases the incidence of disabling strokes. Moreover, documented or silent atrial fibrillation doubles the rate of cardiovascular death. Lowering blood pressure is strongly recommended, particularly for primary stroke prevention. However, a relatively small percentage of hypertensive patients still achieve the recommended blood pressure goals. The management of atrial fibrillation with respect to stroke prevention is changing. New oral anticoagulants represent a major advancement in long-term anticoagulation therapy in non valvular atrial fibrillation. They have several benefits over warfarin, including improved adherence to the anticoagulation therapy. This is an important issue since non-adherence to stroke prevention medications is a risk factor for first and recurrent strokes.
\end{abstract}

Keywords Blood pressure control · Antihypertensive drugs · ARBs $\cdot$ NOACs $\cdot$ Oral anticoagulants

This article is part of the Topical Collection on Novel Treatments for Hypertension

Carmine Savoia

carmine.savoia@uniroma1.it

1 Clinical and Molecular Medicine Department, Cardiology Unit, Faculty of Medicine and Psychology, Sant'Andrea Hospital, Sapienza University of Rome, Rome, Italy

2 IRCCS Neuromed, Polo Molisano University of Rome La Sapienza, Pozzilli (Is), Italy

\section{Introduction}

Stroke, a recurrent and, to a large degree, preventable disorder, represents the third-common cause of death worldwide. Despite evidence that the incidence of stroke has slightly declined in the western countries and the rate of in-hospital mortality has decreased in stroke patients over the past four decades [1], one-third of the stroke patients still die in the first year, and half of them become permanently disabled [1,2]. It has been reported that the world-wide prevalence of stroke is about 15 million cases per year, and in the USA alone there are approximately 800,000 new patients per year suffering a stroke. The incidence of stroke in developing countries is increasing. Moreover, recurrent strokes still account for $25 \%$ to $30 \%$ of all strokes representing unsuccessful secondary prevention [3-5]. Therefore, both primary and secondary prevention is critical in limiting the burden of cerebrovascular disease worldwide. The purpose of primary stroke prevention is the management of the modifiable cardiovascular risk factors and the clinical conditions that predispose an individual to stroke occurrence, whereas secondary prevention is aimed to additionally target several different pathological conditions that predispose an individual to the occurrence of recurrent stroke.

In a large standardized case-control study performed in 22 countries worldwide over three years of follow-up, ten modifiable risk factors (including hypertension, smoking, abdominal obesity, diet, lack of physical activity, diabetes, alcohol intake, psychosocial stress, depression, cardiac causes, and lipid abnormalities) were associated with $90 \%$ of all strokes. Among these risk factors, hypertension, smoking, waist-to-hip ratio, diet, and alcohol intake were significantly associated with intracerebral haemorrhagic stroke [6]. Evidence-based guidelines focused on primary and secondary prevention suggest that those modifiable risk factors should be targeted in clinical practice in order to reduce the health consequences 
and socio-economic burden of stroke [7]. For the secondary prevention of recurrent stroke risk-stratification according to the presence of diabetes, hyperlipidemia, atrial fibrillation, current tobacco smoking, and hypertension should be performed principally during the hospitalization for acute stroke. Therefore, any effort should be recommended to modify these risk factors in order to reduce the risk of recurrent stroke [7].

This is particularly true for hypertension which is responsible of about $50 \%$ of strokes. Lowering blood pressure in hypertensive patients is strongly recommended, particularly for primary stroke prevention [7-9]. Furthermore, hypertension is also a distinct and major risk factor for the occurrence of atrial fibrillation (AF) [7-9]. In fact, it is a component of several prognostic scoring systems, including CHA2DS2 VASc scores in $\mathrm{AF}$ patients for stroke prevention.

$\mathrm{AF}$ is a serious risk factor for cardiovascular patients since it is associated with a high risk of cardiovascular complications, hospitalization, and death. Most importantly, AF increases five fold the risk of stroke and worsens the clinical outcome in patients who experienced stroke, in view of the fact that $\mathrm{AF}$ is associated with increased incidence of disabling strokes, particularly when associated to other cardiovascular risk factors, including hypertension [7, 9].

In this review we will focus on the current evidence of hypertension and AF management for stroke prevention.

\section{Hypertension and Stroke}

Hypertension is one of the major and independent cardiovascular risk factors and contributes to the development of target organ damage and cardiovascular and cerebrovascular events. Both systolic and diastolic hypertension are associated with the occurrence of both primary and recurrent strokes $[8,9,10$, $11 \bullet \bullet]$, mainly when blood pressure remains poorly controlled $[12,13 \cdot]$. Moreover, elevated systolic blood pressure upon hospital discharge after a stroke represents a strong predictor of early recurrence of further cerebrovascular events [14]. Notably, a correlation has been reported between the prevalence of hypertension and the mortality for stroke [15], which is significantly higher after a recurrent stroke compared to a primary stroke [16].

Over the past forty years, randomized controlled trials (most of them versus placebo) have provided evidence that lowering blood pressure with different classes of antihypertensive drugs results in risk reduction for major clinical cardiovascular outcomes, including fatal and nonfatal stroke in hypertensive individuals $[8,17]$. This is strikingly evident for primary stroke prevention of any type [18]. In particular, a recent meta-analysis including more than 50,000 patients has shown that lowering blood pressure provided similar relative protection for all levels of baseline cardiovascular risk, although progressively greater absolute risk reductions for higher levels of baseline risk were observed [19••].

Post-hoc analysis of randomized data suggest that the reduction of fatal and non fatal cardiovascular outcomes are, in part, due to the regression of the alterations in the target organ damage, such as the structural alterations induced by hypertension in the cardiovascular system (i.e., left ventricular hypertrophy and remodelling, fibrosis, vascular remodelling, intima-media-thickness, and urinary protein excretion) $[20,21]$.

Undoubtedly, reducing blood pressure is the most important step in stroke prevention [22], even for patients at low-tomoderate cardiovascular risk and/or with baseline blood pressure in the range of grade 1 hypertension [23-25], although a large part of supporting evidence is provided by meta-analyses including a relatively small number of patients [23, 24]. However, less clear is the approach for lowering blood pressure in patients after a stroke. This is due to the paucity of published trials specifically focused on the management of hypertension for recurrent stroke prevention $[11 \bullet \bullet, 12,13 \bullet]$.

Nonetheless, as long as blood pressure is successfully reduced, all antihypertensive regimens are acceptable for stroke prevention [22], mainly in patients who had a previous stroke. Meta-analyses of randomized controlled trials have reported about a $40 \%$ reduction in recurrent stroke risk with blood pressure lowering regimens $[11 \bullet \bullet, 12,26]$. This has been shown without a clear J-curve effect, although this latter finding is not consistent in all the trials [27-31].

The ESH/ESC guidelines suggest treating hypertensive patients with a history of cerebrovascular events with a recommended therapeutic goal of $<140 \mathrm{mmHg}$ [8]. This target may be considered to be higher, to some extent, in elderly hypertensives with previous stroke or transient ischemic attack (TIA) [8]. Importantly, in high-risk patients, the antihypertensive regimen should be carefully monitored in order to avoid the variability of intra-individual blood pressure measurement at follow-up visits. Indeed, this is associated with the increased incidence of stroke [32]. The effects of antihypertensive drugs on blood pressure variability are dose-dependent and are more evident for a specific class of drugs such as calcium antagonists, mainly when used in combination with other antihypertensive drugs [33]. Interestingly, in a largescale observational study, it has been shown that the recommended antihypertensive treatment achieved blood pressure control in a limited number of hypertensive patients seen by general practitioners (GPs) [34]. This highlights the discrepancies between clinical practice and guideline recommendations, suggesting that any effort should be provided in order to fill this gap in clinical practice. Indeed, an increased awareness of stroke risk factors by GPs is associated with improved blood pressure control in the ten-year estimated risk of stroke [35].

Meta-analyses and meta-regression analyses suggested that some differences in stroke prevention may exist among the 
different antihypertensive classes of drugs. Beta-blockers may be inferior to calcium antagonists and renin-angiotensin system (RAS) blockers for stroke prevention [36, 37]. This is possibly due to the lesser effect of beta-blockers in reducing central systolic blood pressure and pulse pressure [38, 39]. Calcium antagonists may have a greater effectiveness on stroke prevention [40-42]. This may be due to more consistent blood pressure control obtained with this class of drugs although a less defined protective effect on the brain circulation could be also advocated [8].

Among RAS blockers, angiotenisn receptor blockers (ARBs) have shown greater cerebrovascular protective effects in clinical trials and meta-analyses compared to different classes of drugs [43, 44]. This is mainly due to the selective blockade of the RAS, which plays a central role in the development and maintenance of the structural and functional alterations in the cardiovascular system, typically associated with stroke occurrence [45-47]. In the MOSES trial (Morbidity and Mortality After Stroke, Eprosartan Compared With Nitrendipine for Secondary Prevention), ARB did demonstrate the ability to reduce stroke recurrence compared to calcium channel blockers, though in a limited population sample [43]. ACE inhibitors did not show similar consistent protective effects; rather, in some trials, ACE inhibitors performed inferiorly to other classes of drugs in preventing stroke [40-42], unless they were used in combination therapy. In secondary stroke prevention in the PROGRESS trial (Perindopril Protection Against Recurrent Stroke Study), ACE inhibitors in combination with diuretics showed a significant reduction of cerebrovascular events [48]. However, this was apparently due mostly to the blood pressure lowering effect of the diuretic indapamide. In fact, combination therapy using a diuretic and another different class of drugs has shown to be successful in stroke prevention, particularly in the elderly and in higher cardiovascular risk patients [45, 49-51]. The use of combination therapy is quite common in clinical practice, since about 70-80\% of treated hypertensive patients may require combination therapy (at least two classes of drugs) in order to achieve the recommended blood pressure goals, particularly in high cardiovascular risk patients. Despite this evidence and the recommendations, a relatively small percentage of hypertensive patients (about 30-40 \%) still achieve recommended blood pressure goals in clinical trials [52], and more than $50 \%$ of patients still receive monotherapy.

\section{Atrial Fibrillation and Stroke}

$\mathrm{AF}$ is one of the most common cardiac arrhythmias, with a relatively high prevalence in the general population (1-2\%) [53]. AF increases the risk of cardiovascular events, including stroke, since AF is present in about $15 \%$ of patients who suffer cerebrovascular events. Interestingly, the risk of stroke is similar in both paroxysmal AF and permanent or persistent AF [54•]; as also, there is evidence that subclinical or silent AF might contribute to $25 \%$ of unexplained strokes [54 $[55]$. Documented AF or subclinical or silent AF doubles the rate of cardiovascular death [56].

Several cardiovascular risk factors are associated and predispose an individual to the occurrence of AF. Among those risk factors, age, hypertension, and diabetes correlate to the development of AF [6, 57-59]. These risk factors are also associated with thrombembolic complications of AF, mainly stroke. Several risk models are available for risk stratification and prevention of thromboembolism in patients with AF [7, 9]. In all of these models, hypertension is present and represents an important risk factor. The CHA2DS2-Vasc-score is a simple clinical approach to assess the individual risk for thromboembolic complications in patients with diagnosed AF. In those patients with a score $>1$, a net benefit from antithrombotic treatment in primary and secondary prevention has been shown [7, 9]. Nevertheless, AF may be silent and, therefore, unrecognized in about $40 \%$ of AF patients [54•, 60•]. Time and duration of AF per day represent additional risk factors for cerebrovascular events, since it has been shown that one hour in daily AF time resulted in increased risk of stroke by about $3 \%$ [61•]. Patients with silent AF are, indeed, at high risk for stroke which may occur in more than $30 \%$ of patients [54•, 60•]. It is likely those patients do not receive anticoagulants, and this may increase the risk of stroke [62•], yet the benefits of antithrombotic treatment in patients with subclinical AF remain to be further studied [63]. Thus, monitoring AF episodes with electrocardiography (ECG) recording devices may become crucial and this approach should be considered in select patients [7, 9, 64].

In relation to the risk score, most patients with AF should receive anticoagulant therapy to reduce the risk of stroke. It has been shown that the relative risk of ischemic stroke was decreased by $67 \%$, and the risk of all-cause mortality was reduced by $27 \%$ by using oral anticoagulants [65]. Antithrombotic treatment with the vitamin $\mathrm{K}$ antagonist (VKA) warfarin is effective in either primary or secondary prevention of thromboembolic events in AF patients. However, quite recently, novel oral anticoagulants (NOACs) that do not require international normalized ratio (INR) monitoring have been introduced with promising results in patients with non valvular AF [66]. NOACs include direct thrombin inhibitors, dabigatran, factor $\mathrm{Xa}$ inhibitors, rivaroxaban, apixaban, and edoxaban; they have been shown to be noninferior and sometimes superior to warfarin [7, 9, 67], and have reduced all-cause mortality in different clinical trials [67]. The selection of an anticoagulant drug should be individualized based on renal and hepatic function, potential drug interaction, patient preference, tolerability, previous anticoagulation effectiveness and safety, as well as cost [66, 67]. Anticoagulants are associated with a risk of bleeding 
complications. Therefore, the possibility of anticoagulation should be weighted against the bleeding risk of the patient. However, NOACs, compared with VKAs, are associated with less intracranial hemorrhage and are generally preferred over VKAs [66, 67].

It should be noted that, despite the evidence that long-term oral anticoagulation for secondary stroke prevention in $\mathrm{AF}$ is highly effective, it is frequently not started or discontinued in clinical practice. In a recent prospective cohort study the nonadherence to oral anticoagulation in stroke patients resulted from fear of potential complications (such as bleeding) or inconvenience of regular international normalized ratio measurements and physicians' concerns regarding functional status of patients [68 ${ }^{\bullet}$. Nevertheless, there is evidence that persistence with therapy may be better with NOACs than with warfarin $[67,68 \cdot, 69]$. It is important to note that in most studies addressing the efficacy of VKA or NOACs in patients with $\mathrm{AF}$, blood pressure changes and the role of antihypertensive therapy are underreported or even not analyzed [70••].

\section{Hypertension and Atrial Fibrillation}

High blood pressure is an established risk factor for AF which in turn is the most prevalent concomitant condition in hypertensive patients [7,9]. AF greatly enhances the disability and mortality in hypertensive subjects [71-73]. Blood pressure values even in the high normal range are associated with the development of this arrhythmia [74]. AF may be associated with different functional and structural alterations induced by hypertension in the cardiovascular system, including structural changes in the heart (i.e., left atrium enlargement), fibrosis, heart failure, neurohormonal activation, and atherosclerosis [45-47]. In particular, a pooled analysis of data from AFFI RM (The Atrial Fibrillation Follow-up Investigation of Rhythm Management) and AF-CHF (Atrial Fibrillation and Congestive Heart Failure) patients with paroxysmal or persistent AF showed that systolic blood pressure is an important determinant of recurrent $\mathrm{AF}$ burden only in patients with left ventricular dysfunction (LVEF $\leq 40 \%$ ) but not in those with preserved ventricular function [75.].

In hypertensive patients, AF is a common cause of cardiovascular complications, including stroke [76, 77]; thus, prevention of new episodes of AF is warranted, particularly in hypertensive patients [77]. Antihypertensive treatment may contribute to a reduction of risk, and it seems that some classes of drugs are superior to others in the prevention of new-onset $\mathrm{AF}$ and stroke prevention [67]. This is related to the concomitant clinical conditions and to the distinctive property of a specific drug in reversing structural cardiac damage caused by hypertension $[78,79]$.

In particular, ARBs seems to be more effective in preventing the first occurrence of $\mathrm{AF}$ than other drugs such as beta-blockers and calcium antagonists in hypertensive patients with structural heart disease (left ventricular hypertrophy or dysfunction) [80-84] and no history of $\operatorname{AF}[81,85,86]$. However clinical trials have shown that ARBs were less able to prevent recurrences of paroxysmal or persistent $\mathrm{AF}$ [87, 88•, 89], and also did not improve survival in patients with established AF. Thus, the beneficial effects of ARBs may be limited to the prevention of incident $\mathrm{AF}$ in patients with hypertension and structural heart disease [88 $]$ and no history of AF $[8,67]$. This may be due to the beneficial effects on atrial stretch, interstitial fibrosis, inflammation, and structural remodelling. On the other hand, it should be noted that while ARBs may be helpful in prevention of $\mathrm{AF}$ in patients with early or reversible cardiac structural changes [45, 80], they may be much less effective in patients with more advanced or heterogeneous cardiac disease [87].

Nevertheless, a recent meta-analysis indicates that telmisartan seems to be more effective than other antihypertensive drugs in preventing AF recurrences among hypertensive patients with paroxysmal AF, beyond blood pressure reduction [90•]. Several mechanisms are postulated, including strong binding affinity to angiotensin II type 1 receptors, the specific property to block potassium channels involved in the ultra-rapid delayed rectifier currents in atrial myocytes [91] and an effect in facilitating parasympathetic activity as well as reducing QT dispersion [92]. These findings have not been confirmed in high-risk patients with established atherosclerotic disease [93, 94].

In patients with $\mathrm{AF}$ and a high ventricular rate, betablockers and non-dihydropyridine calcium antagonists are recommended [7, 9]; also, beta-blockers and mineralocorticoid antagonists may prevent atrial fibrillation, particularly in patients with heart failure $[95,96]$.

Hypertensive patients with AF should be assessed for the risk of thromboembolism by the above mentioned scores (i.e., CHA2DS2-Vasc-score) [7, 9]. Where indicated by the score, those patients should receive oral anticoagulation therapy [7, $9,65]$. In patients receiving anticoagulation therapy, effective blood pressure control should be warranted in order to reduce bleeding events $[97 \bullet \bullet]$.

\section{Conclusion}

Hypertension is the most common cardiovascular disorder and $\mathrm{AF}$ is the most common clinically relevant arrhythmia. Hypertension predisposes an individual to the development of $\mathrm{AF}$ and these conditions frequently coexist. Their prevalence increases rapidly with aging and is associated with the occurrence of both primary and recurrent cerebrovascular events. Stroke constitutes a clinical and socio-economic burden, due to the high prevalence of disability after the first year following an acute event. Stroke risk can be substantially reduced by 
using the medical measures that have been proven in many randomized trials. Hence, prescription of evidenced-based stroke prevention medications in AF and/or hypertensisve patients is mandatory. However, it is still a challenge to translate the efficacy of the interventions reported in clinical trials into everyday clinical practice. Blood pressure control is extremely relevant for primary and secondary cardiovascular and cerebrovascular prevention, although only $30-40 \%$ of patients with arterial hypertension achieve the recommended blood pressure goals in clinical trials [34, 35, 52]. Therefore, efforts should be made to improve blood pressure control, especially through the use of effective and well tolerated combination therapies in hypertensive patients, particularly those with high cardiovascular risk profiles.

The management of AF with respect to stroke prevention is changing. The antithrombotic therapy is challenging due to the overlap of ischemic stroke predictors such as the CHA2DS2 VASc score and major bleeding scores (i.e., HAS BLED score) [7-9, 66]. Currently, NOACs represent a major advance in long-term anticoagulation therapy in non valvular AF and have many benefits over warfarin; not secondly, this class of drugs is characterized by improved adherence to anticoagulation therapy. This is an extremely important issue since non-adherence to stroke prevention medications is a risk factor for first and recurrent strokes [98•]. Finally, the future management of AF should combine prevention and personalised treatment of AF that results in an effective prediction of $\mathrm{AF}$ and mortality and morbidity prevention.

\section{Compliance with Ethics Guidelines}

Conflict of Interest Carmine Savoia and Massimo Volpe report personal fees from Daiichi-Sankyo Italia. Lidia Sada declares no conflict of interest.

Human and Animal Rights and Informed Consent This article does not contain any studies with human or animal subjects performed by any of the authors.

\section{References}

Papers of particular interest, published recently, have been highlighted as:

- Of importance

•- Of major importance

1. Redon J, Olsen MH, Cooper RS, et al. Stroke mortality trends from 1990 to 2006 in 39 countries from Europe and Central Asia: implications for control of high blood pressure. Eur Heart J. 2011;32: 1424-31.

2. Brown DW, Giles WH, Greenlund KJ. Blood pressure parameters and risk of fatal stroke, NHANES II mortality study. Am J Hypertens. 2007;20:338-41.
3. Hong KS, Yegiaian S, Lee M, Lee J, Saver JL. Declining stroke and vascular event recurrence rates in secondary prevention trials over the past 50 years and consequences for current trial design. Circulation. 2011;123:2111-9.

4. Lloyd-Jones D, Adams R, Carnethon M, American Heart Association Statistics Committee and Stroke Statistics Subcommittee, et al. Heart disease and stroke statistics-2009 update: a report from the American Heart Association Statistics Committee and Stroke Statistics Subcommittee. Circulation. 2009;119:480-6.

5. Go AS, Mozaffarian D, Roger VL, et al. Heart disease and stroke statistics-2014 update report from the American Heart Association. Circulation. 2014;129:e28-292.

6. O'Donnell MJ, Xavier D, Liu L, INTERSTROKE investigators, et al. Risk factors for ischaemic and intracerebral haemorrhagic stroke in 22 countries (the INTERSTROKE study): a case-control study. Lancet. 2010;376:112-23.

7. Kernan WN, Ovbiagele B, Black HR, et al. Guidelines for the prevention of stroke in patients with stroke and transient ischemic attack a guideline for health care professionals from the American Heart Association/American Stroke Association. Stroke. 2014;45(7):2160-236.

8. Mancia G, Fagard R, Narkiewicz K, et al. 2013 ESH/ESC guidelines for the management of arterial hypertension: the Task Force for the Management of Arterial Hypertension of the European Society of Hypertension (ESH) and of the European Society of Cardiology (ESC). Eur Heart J. 2013;34(28):2159-219.

9. Camm AJ, Lip GY, De Caterina R, et al. 2012 focused update of the ESC Guidelines for the management of atrial fibrillation: an update of the 2010 ESC Guidelines for the management of atrial fibrillation. Eur Heart J. 2012;33:2719-3274.

10. Lewington S, Clarke R, Qizilbash N, Peto R, Collins R, Prospective Studies Collaboration. Age-specific relevance of usual blood pressure to vascular mortality: a meta-analysis of individual data for one million adults in 61 prospective studies. Lancet. 2002;360:190313.

11.• Boan AD, Lackland DT, Ovbiagele B. Lowering of blood pressure for recurrent stroke prevention. Stroke. 2014;45:2506-13. This review article critically analyzes the published evidences from randomized clinical trials, expert consensus guideline recommendations, and key literature gaps and provides an update of relevant topics and recent data concerning lowering blood pressure for recurrent stroke prevention.

12. Lawes CM, Bennett DA, Feigin VL, Rodgers A. Blood pressure and stroke: an overview of published reviews. Stroke. 2004;35: 776-85.

13. Roumie CL, Zillich AJ, Bravata DM, et al. Hypertension treatment intensification among stroke survivors with uncontrolled blood pressure. Stroke. 2015;46:465-70. This study examined the blood pressure values one year after stroke discharge and its association with treatment intensification among a national cohort of Veterans discharged after acute ischemic stroke. The results showed that secondary stroke prevention efforts should focus on initiation and review of blood pressure lowering drugs before acute stroke discharge. Moreover, this study strongly recommended drug titration and patient medication adherence counselling.

14. Bath P. High blood pressure as risk factor and prognostic predictor in acute ischaemic stroke: when and how to treat it? Cerebrovasc Dis. 2004;17 suppl 1:51-7.

15. Wolf-Maier K, Cooper RS, Banegas JR, et al. Hypertension prevalence and blood pressure levels in 6 European countries, Canada and the United States. JAMA. 2003;289:2363-9.

16. Hardie K, Hankey GJ, Jamrozik K, Broadhurst RJ, Anderson C. Ten-year risk of first recurrent stroke and disability after first-ever 
stroke in the Perth Community Stroke Study. Stroke. 2004;35:7315 .

17. Collins R, Mac Mahon S. Blood pressure, antihypertensive drug treatment and the risks of stroke and of coronary heart disease. $\mathrm{Br}$ Med Bull. 1994;50:272-98.

18. Lackland DT, Roccella EJ, Deutsch AF, American Heart Association Stroke Council; Council on Cardiovascular and Stroke Nursing; Council on Quality of Care and Outcomes Research; Council on Functional Genomics and Translational Biology, et al. Factors influencing the decline in stroke mortality: a statement from the American Heart Association/American Stroke Association. Stroke. 2014;45:315-53.

19.• The Blood Pressure Lowering Treatment Trialists' Collaboration. Blood pressure-lowering treatment based on cardiovascular risk: a meta-analysis of individual patient data. Lancet. 2014;384:591-8.

This meta-analysis showed that the antihypertensive treatment induces a progressively greater absolute risk reduction at higher levels of baseline risk. Therefore, this study further highlights the concept that, for the management of hypertensive patients, the physician should take into account the global cardiovascular risk and should target patients at greatest cardiovascular risk.

20. Devereux RB, Wachtell K, Gerdts E, et al. Prognostic significance of left ventricular mass change during treatment of hypertension. JAMA. 2004;292:2350-6.

21. Ibsen $\mathrm{H}$, Olsen $\mathrm{MH}$, Wachtell $\mathrm{K}$, et al. Reduction in albuminuria translates to reduction in cardiovascular events in hypertensive patients: losartan intervention forendpoint reduction in hypertension study. Hypertension. 2005;45:198-202.

22. Gueyffier F, Boissel JP, Boutitie F, et al. Effect of antihypertensive treatment in patients having already suffered from stroke. Gathering the evidence. The INDANA (INdividual Data ANalysis of Antihypertensive intervention trials) Project Collaborators. Stroke. 1997;28:2557-62.

23. Medical Research Council Working Party. MRC trial on treatment of mild hypertension: principal results. Br Med J. 1985;291:97104.

24. Management Committee. The Australian therapeutic trial in mild hypertension. Lancet. 1980;1:1261-7.

25. Zhang Y, Zhang X, Liu L, Zanchetti A. Is a systolic blood pressure target $<140 \mathrm{mmHg}$ indicated in all hypertensives? Subgroup analyses of findings from the randomized FEVER trial. Eur Heart J. 2011;32:1500-8.

26. Turnbull F, Blood Pressure Lowering Treatment Trialists' Collaboration. Effects of different blood-pressure-lowering regimens on major cardiovascular events: results of prospectivelydesigned overviews of randomised trials. Lancet. 2003;362:152735 .

27. Messerli FH, Mancia G, Conti CR, et al. Dogma disputed: can aggressively lowering blood pressure in hypertensive patients with coronary artery disease be dangerous? Ann Intern Med. 2006;144: 884-93.

28. Sleight P, Redon J, Verdecchia P, et al. Prognostic value of blood pressure in patients with high vascular risk in the Ongoing Telmisartan Alone and in combination with Ramipril Global Endpoint Trial study. J Hypertens. 2009;27:1360-9.

29. Mancia G, Schumacher H, Redon J, et al. Blood pressure targets recommended by guidelines and incidence of cardiovascular and renal events in the Ongoing Telmisartan Alone and in Combination With Ramipril Global Endpoint Trial (ONTARGET). Circulation. 2011;124:1727-36.

30. Ovbiagele B, Diener HC, Yusuf S, et al. Level of systolic blood pressure within the normal range and risk of recurrent stroke. JAMA. 2011;306:2137-44. 326.

31. Redon J, Mancia G, Sleight P, et al. Safety and efficacy of low blood pressures among patients with diabetes: subgroup analyses from the ONTARGET (ON going Telmisartan Alone and in combination with Ramipril Global Endpoint Trial). J Am Coll Cardiol. 2012;59:74-83.

32. Rothwell PM, Howard SC, Dolan E, et al. Prognostic significance of visit-to-visit variability, maximum systolic blood pressure and episodic hypertension. Lancet. 2010;375:895-905.

33. Webb AJ, Rothwell PM. Effect of dose and combination of antihypertensives on interindividual blood pressure variability: a systematic review. Stroke. 2011;42:2860-5.

34. Mancia G, Ambrosioni E, Rosei EA, Leonetti G, Trimarco B, Volpe $\mathrm{M}$, et al. Blood pressure control and risk of stroke in untreated and treated hypertensive patients screened from clinical practice: results of the For Life study. J Hypertens. 2005;23(8):1575-81.

35. Volpe M, Rosei EA, Ambrosioni E, Leonetti G, Trimarco B, Mancia G. Reduction in estimated stroke risk associated with practice-based stroke-risk assessment and awareness in a large, representative population of hypertensive patients: results from the ForLife study in Italy. J Hypertens. 2007;25(12):2390-7.

36. Wiyonge CS, Bradley HA, Volmink J, Mayosi BM, Mbenin A, Opie LH. Beta-blockers for hypertension. Cochrane Database Syst Rev. 2012;11:CD002003.

37. Bradley HA, Wiyonge CS, Volmink VA, Mayosi BM, Opie LH. How strong is the evidence for use of beta-blockers as first line therapy for hypertension? J Hypertens. 2006;24:2131-41.

38. Williams B, Lacy PS, Thom SM, et al. Differential impact of blood pressure-lowering drugs on central aortic pressure and clinical outcomes: principal results of the Conduit Artery Function Evaluation (CAFE) study. Circulation. 2006;113:1213-25.

39. Boutouyrie P, Achouba A, Trunet P, Laurent S. Amlodipinevalsartan combination decreases central systolic blood pressure more effectively than the amlodipine-atenolol combination: the EXPLOR study. Hypertension. 2010;55:1314-22.

40. Law MR, Morris JK, Wald NJ. Use of blood pressure lowering drugs in the prevention of cardiovascular disease: meta-analysis of 147 randomised trials in the context of expectations from prospective epidemiological studies. BMJ. 2009;338:b1665.

41. Blood Pressure Lowering Treatment Trialists' Collaboration. Effects of different blood-pressure-lowering regimens on major cardiovascular events: results of prospectively- designed overviews ofrandomised trials. Lancet. 2003;362:1527-35.

42. Verdecchia P, Reboldi G, Angeli F, et al. Angiotensin-converting enzyme inhibitors and calcium channel blockers for coronary heart disease and stroke prevention. Hypertension. 2005;46:386-92.

43. Schrader J, Luders S, Kulschewski A, MOSES Study Group, et al. Morbidity and mortality after stroke, eprosartan compared with nitrendipine for secondary prevention: principal results of a prospective randomized controlled study (MOSES). Stroke. 2005;36: 1218-26.

44. Reboldi G, Angeli F, Cavallini C, Gentile G, Mancia G, Verdecchia P. Comparison between angiotensin-converting enzyme inhibitors and angiotensin receptor blockers on the risk of myocardial infarction, stroke and death: a meta-analysis. J Hypertens. 2008;26:1282-9.

45. Dahlof B, Devereux RB, Kjeldsen SE, LIFE Study Group, et al. Cardiovascular morbidity and mortality in the Losartan Intervention For Endpoint reduction in hypertension study (LIFE): a randomised trial against atenolol. Lancet. 2002;359:995-1003.

46. Savoia C, Burger D, Nishigaki N, Montezano A, Touyz RM. Angiotensin II and the vascular phenotype in hypertension. Expert Rev Mol Med. 2011;13:e11.

47. Savoia C, Sada L, Zezza L, et al. Vascular inflammation and endothelial dysfunction in experimental hypertension. Int $\mathrm{J}$ Hypertens. 2011;2011:281240.

48. PROGRESS Collaborative Group. Randomised trial of a perindoprilbased blood-pressure-lowering regimen among 6105 individuals with previous stroke or transient ischaemic attack. Lancet. 2001;358:1033-41. 
49. SHEP Co-operative Research Group. Prevention of stroke by antihypertensive drug treatment in older persons with isolated sistoli hypertension. Final results of the Systolic Hypertension in the Elderly Program (SHEP). JAMA. 1991;265:3255-64.

50. Lithell H, Hansson L, Skoog I, et al. The Study on Cognition and Prognosis in the Elderly (SCOPE): principal results of a randomized double-blind intervention trial. J Hypertens. 2003;21:875-86.

51. Coope J, Warrender TS. Randomised trial of treatment of hypertension in elderly patients in primary care. BMJ. 1986;293:1145-51.

52. Thoenes M, Neuberger HR, Volpe M, Khan BV, Kirch W, Böhm M. Antihypertensive drug therapy and blood pressure control in men and women: an international perspective. J Hum Hypertens. 2010;24(5):336- 44.

53. Stewart S, Hart CL, Hole DJ, McMurray JJV. Population prevalence, incidence, and predictors of atrial fibrillation in the Renfrew/Paisley study. Heart. 2001;86(5):516-21.

54. Healey JS, Connolly SJ, Gold MR, et al. Subclinical atrial fibrillation and the risk of stroke. New Engl J Med. 2012;366(2):120-9. This study investigated the occurrence of subclinical atrial fibrillation after three months follow-up in a large cohort of hypertensive patients with no history of atrial fibrillation, and in whom a pacemaker or defibrillator had recently been implanted. Interestingly, clinically silent atrial fibrillation occurred frequently in patients with pacemakers and was associated with a significantly increased risk of ischemic stroke or systemic embolism. This study highlights the issue that monitoring the episodes of atrial fibrillation with ECG recording devices could be crucial in selective patients.

55. Tayal AH, Tian M, Kelly KM, et al. Atrial fibrillation detected by mobile cardiac outpatient telemetry in cryptogenic TIA or stroke. Neurology. 2008;71(21):1696-701

56. Stewart S, Hart CL, Hole DJ, McMurray JJ. A population-based study of the long-term risks associated with atrial fibrillation: 20year follow-up of the Renfrew/Paisley study. Am J Med. 2002;113(5):359-64.

57. Kotseva K, Wood D, De Backer G, De Bacquer D, Pyorala K, Keil U. Cardiovascular prevention guidelines in daily practice: a comparison of EUROASPIRE I, II, and III surveys in eight European countries. Lancet. 2009;373(9667):929-40.

58. Schnabel RB, Sullivan LM, Levy D, et al. Development of a risk score for atrial fibrillation (Framingham Heart Study): a community-based color study. Lancet. 2009;373:739-45.

59. Schnabel RB, Aspelund T, Li G, Sullivan LM, Suchy-Dicey A, Harris $\mathrm{TB}$, et al. Validation of an atrial fibrillation risk algorithm in whites and African-Americans. Arch Intern Med. 2010;170:1909-17.

60. Lowres N, Neubeck L, Redfern J, Ben Freedman S. Screening to identify unknown atrial fibrillation: a systematic review. Thromb Haemostas. 2013;110(2):213-22. This systematic review of clinical trials by searching electronic medical databases, reference lists and grey literature was aimed to investigate the occurrence of unknown atrial fibrillation. Interestingly, in patients with previously unknown atrial fibrillation, $67 \%$ were at high risk of stroke. Screening can identify $1.4 \%$ of the population $\geq 65$ years with previously undiagnosed atrial fibrillation. Therefore community atrial fibrillation screening strategies in older age groups at risk could potentially reduce the socio-economic burden of the thromboembolic complication of atrial fibrillation. Indeed, many of those patients would benefit from oral anticoagulant therapy for stroke prevention.

61. Boriani G, Glotzer TV, Santini M, et al. Device-detected atrial fibrillation and risk for stroke: an analysis of $>10000$ patients from the SOS $\mathrm{AF}$ project (Stroke prevention Strategies based on Atrial Fibrillation information from implanted devices). Eur Heart J. 2014;35(8):508-16. This study was performed to assess the association between maximum daily atrial fibrillation burden and risk of ischaemic stroke, based on a pooled analysis of individual patient data from five prospective studies in patients with cardiac implanted electronic devices. The results showed that the device-detected atrial fibrillation burden is associated with an increased risk of ischemic stroke in a relatively unselected population of patients. In particular, one hour in daily atrial fibrillation time resulted in increased risk of stroke. This finding could be relevant for the management of stroke prevention in patients with atrial fibrillation with respect to the timing and the appropriate decision-making on anticoagulation treatment.

62. Quinn FR, Gladstone D. Screening for undiagnosed atrial fibrillation in the community. Curr Opin Cardiol. 2014;29(1):28-35. This review article further underlines the importance of the screening for silent atrial fibrillation, since this condition is associated with increased cardiovascular mortality, due to the fact that these patients do not receive anticoagulants. Thus, increased attention should be directed towards screening for silent atrial fibrillation. Though, whether this will translate into improved outcomes for patients remains to be proven.

63. Savelieva I, Camm AJ. Clinical relevance of silent atrial fibrillation: prevalence, prognosis, quality of life, and management. J Interv Card Electr. 2000;4(2):369-82.

64. Helms TM, Duong G, Zippel-Schultz B, Tilz RR, Kuck KH, Karle $\mathrm{CA}$. Prediction and personalised treatment of atrial fibrillationstroke prevention: consolidated position paper of CVD professionals. EPMA J. 2014;5(1):15.

65. Hart RG, Pearce LA, Aguilar MI. Meta-analysis: antithrombotic therapy to prevent stroke in patients who have nonvalvular atrial fibrillation. Ann Intern Med. 2007;146(12):857-67.

66. Weitz JI. Expanding use of new oral anticoagulants F1000. Prime Rep. 2014;6:93.

67. Manolis AJ, Rosei EA, Coca A, et al. Hypertension and atrial fibrillation: diagnostic approach, prevention and treatment. Position paper of the Working Group 'Hypertension Arrhythmias and Thrombosis' of the European Society of Hypertension. J Hypertens. 2012;30:239-52.

68. Gumbinger C, Holstein T, Stock C, Rizos T, Horstmann S, Veltkamp R. Reasons underlying non-adherence to and discontinuation of anticoagulation in secondary stroke prevention among patients with atrial fibrillation. Eur Neurol. 2015;73(3-4):184-91. This prospective, observational, single-center cohort study showed that non-adherence to oral anticoagulants in stroke patients results from fear of potential complications or inconvenience and physicians' concerns regarding functional status. This should be taken into account to avoid under-treatment of patients with atrial fibrillation at risk for stroke.

69. Zalesak M, Siu K, Francis K, et al. Higher persistence in newly diagnosed nonvalvular atrial fibrillation patients treated with dabigatran versus warfarin. Circ Cardiovasc Qual Outcomes. 2013;6:567-74.

70.• Manolis A, Doumas M, Poulimenos L, Kallistratos M, Mancia G. The unappreciated importance of blood pressure in recent and older atrial fibrillation trials. J Hypertens. 2013;31(11):2109-17. This paper highlights the evidence that blood pressure changes and the role of antihypertensive therapy are underreported or even not analyzed in most studies addressing the efficacy of VKA or NOACs in patients with atrial fibrillation. Since antithrombotic therapy reduces significantly the risk for ischemic stroke in patients with atrial fibrillation at the expense of increased risk of intracranial bleeding particularly when blood pressure is poorly controlled, regular blood pressure recording should be mandatory in all future studies with antithrombotic therapy, as well as in common clinical practice in patients with atrial fibrillation on treatment with oral anticoagulants.

71. Kannel WB, Wolf PA, Benjamin EJ, Levy D. Prevalence, incidence, prognosis and predisposing conditions for atrial fibrillation: population-based estimates. Am J Cardiol. 1998;82:2N-9. 
72. Vagaonescu TD, Wilson AC, Kostis JB. Atrial fibrillation and isolated systolic hypertension: the systolic hypertension in the elderly program and systolic hypertension in the elderly program-extension study. Hypertension. 2008;51:1552-6.

73. Conen D, Tedrow UB, Koplan BA, Glynn RJ, Buring JE, Albert CM. Influence of systolic and diastolic blood pressure on the risk of incident atrial fibrillation in women. Circulation. 2009;119:2146-52.

74. Grundvold I, Skretteberg PT, Liestol K, et al. Upper normal blood pressures predict incident atrial fibrillation in healthy middle-aged men: a 35-year follow-up study. Hypertension. 2012;59:198-204.

75. Tremblay-Gravel M, White M, Roy D, Leduc H, et al. Blood pressure and atrial fibrillation: a combined AF-CHF and AFFIRM analysis. J Cardiovasc Electrophysiol. 2015. doi:10.1111/jce.12652. This is a pooled analysis of patient-level data from AFFIRM and AFCHF trials, conducted on about 3000 patients with paroxysmal or persistent AF. Interestingly this study showed that systolic blood pressure is an important determinant of recurrent atrial fibrillation burden in patients with left ventricular dysfunction but not in those with preserved ventricular function.

76. Kirchhof P, Bax J, Blomstrom-Lundquist C, et al. Early and comprehensive management of atrial fibrillation: executive summary of the proceedings from the 2nd AFNET-EHRA consensus conference 'research perspectives in AF'. Eur Heart J. 2009;30:2969-2977c.

77. Kirchhof P, Lip GY, Van Gelder IC, et al. Comprehensive risk reduction in patients with atrial fibrillation: emerging diagnostic and therapeutic options. Executive summary of the report from the 3rd AFNET/EHRA consensus conference. Thromb Haemost. 2011;106:1012-9.

78. Gerdts E, Wachtell K, Omvik P, et al. Left atrial size and risk of major cardiovascular events during antihypertensive treatment: losartan intervention for endpoint reduction in hypertension trial. Hypertension. 2007;49:311-6.

79. Okin PM, Wachtell K, Devereux RB, et al. Regression of electrocardiographic left ventricular hypertrophy and decreased incidence of new-onset atrial fibrillation in patients with hypertension. JAMA. 2006;296:1242-8.

80. Wachtell K, Lehto M, Gerdts E, et al. Angiotensin II receptor blockade reduces new-onset atrial fibrillation and subsequent stroke compared with atenolol: the Losartan Intervention For End Point Reduction in Hypertension (LIFE) study. J Am Coll Cardiol. 2005;45:712-9.

81. Schmieder RE, Kjeldsen SE, Julius S, McInnes GT, Zanchetti A, Hua TA. Reduced incidence of new-onset atrial fibrillation with angiotensin II receptor blockade: the VALUE trial. J Hypertens. 2008;26:403-11.

82. Cohn JN, Tognoni G. A randomized trial of the angiotensinreceptor blocker valsartan in chronic heart failure. N Engl J Med. 2001;345:1667-75.

83. Vermes E, Tardif JC, Bourassa MG, et al. Enalapril decreases the incidence of atrial fibrillation in patients with left ventricular dysfunction: insight from the Studies Of Left Ventricular Dysfunction (SOLVD) trials. Circulation. 2003;107:2926-31.

84. Ducharme A, Swedberg K, Pfeffer MA, et al. Prevention of atrialfibrillation inpatients with symptomatic chronic heart failure byc andesartan in the Candesartanin Heartfailure: Assessment of Reductionin Mortality and morbidity (CHARM) program. Am Heart J. 2006;152:86-92.

85. Schneider MP, Hua TA, Bohm M, Wachtell K, Kjeldsen SE, Schmieder RE. Prevention of atrial fibrillation by reninangiotensin system inhibition: a meta-analysis. J Am Coll Cardiol. 2010;55:2299-307.

86. Tveit A, Grundvold I, Olufsen M, et al. Candesartan in the prevention of relapsing atrial fibrillation. Int J Cardiol. 2007;120:85-91.

87. The GISSI-AF Investigators. Valsartan for prevention of recurrent atrial fibrillation. N Engl J Med. 2009;360:1606-17.
88. Goette A, Schon N, Kirchhof P, et al. Angiotensin II-antagonist in paroxysmal atrial fibrillation (ANTIPAF) trial. Circ Arrhythm Electrophysiol. 2012;5:43-51. This trial showed that ARB therapy per se does not reduce the number of atrial fibrillation episodes in patients with documented paroxysmal AF without structural heart disease. This further underlines that the clinical efficacy of ARBs to prevent atrial fibrillation occurs mainly in patients with structural heart disease.

89. The Active I Investigators, Yusuf S, Healey JS, Pogue J, et al. Irbesartan in patients with atrial fibrillation. N Engl J Med. 2011;364:928-38.

90. Pan G, Zhou X, Zhao J. Effect of telmisartan on atrial fibrillation recurrences in patients with hypertension: a systematic review and meta-analysis. Cardiovasc Ther. 2014;32:184-8. The results of this review and meta-analysis indicate that, among other antihypertensive drugs, telmisartan seems to be more effective in preventing atrial fibrillation recurrences in hypertensive patients with paroxysmal atrial fibrillation. This could have an impact on the choice of the antihypertensive treatment of hypertensive patients at cardiovascular risk.

91. Tu DN, Liao YH, Zou AR, Du YM, Run Q, Wang XP, et al. Electropharmacological properties of telmisartan in blocking hKv1.5 and HERG potassium channels expressed on Xenopus laevis oocytes. Acta Pharmacol Sin. 2008;29:913-22.

92. Galetta F, Franzoni F, Fallahi P, et al. Effect of telmisartan on QT interval variability and autonomic control in hypertensive patients with left ventricular hypertrophy. Biomed Pharmacother. 2010;64: 516-20.

93. Yusuf S, Teo K, Anderson C, for the Telmisartan Randomized Assessment Study in ACE intolerant subjects with cardiovascular disease (TRANSCEND) Investigators, et al. Effects of the angiotensin-receptor blocker telmisartan on cardiovascular events in high-risk patients intolerant to angiotensin-converting enzyme nhibitors: a randomised controlled trial. Lancet. 2008;372:1174-83.

94. Yusuf S, Diener HC, Sacco RL, et al. Telmisartan to prevent recurrent stroke and cardiovascular events. N Engl J Med. 2008;359: 1225-37.

95. Nasr IA, Bouzamondo A, Hulot JS, Dubourg O, Le Heuzey JY, Lechat P. Prevention of atrial fibrillation onset by beta-blocker treatment in heart failure: a meta-analysis. Eur Heart J. 2007;28:457-62.

96. Swedberg K, Zannad F, McMurray JJ, EMPHASIS-HF Study Investigators, et al. Eplerenone and atrial fibrillation in mild systolic heart failure: results from the EMPHASISHF (Eplerenone in Mild Patients Hospitalization and Survival Study in Heart Failure) study. J Am Coll Cardiol. 2012;59:1598-603.

97.• Arima H, Anderson C, Omae T, et al. Effects of blood pressure lowering on intracranial and extracranial bleeding in patients on antithrombotic therapy: the PROGRESS trial. Stroke. 2012;43: 1675-7. This is a subsidiary analysis of the PROGRESS trial that further highlights the concept that blood pressure reduction provides protection against intracranial bleeding among patients with cerebrovascular disease including those receiving antithrombotic therapy. Indeed among patients on antithrombotic therapy, the lowest risk of intracranial bleeding was observed in participants with the lowest follow-up systolic blood pressure levels (median, $113 \mathrm{~mm} \mathrm{Hg}$ ).

98. Bushnell C, Arnan M, Han S. A new model for secondary prevention of stroke: transition coaching for stroke. Front Neurol. 2014;5: 219. In this study, a new model of post-discharge prevention care was proposed, that measures and addresses medicationtaking (transition coaching for stroke or TRACS). This is an interest and highly important issue, since non-adherence to stroke prevention medications is a risk factor for stroke. Moreover, there are no clear guidelines for processes to recognize and address medication non-adherence in stroke patients. 